\title{
AGGRESSIVE SURGERY FOR TREATING A PULMONARY METASTASIS OF A BENIGN GIANT CELL TUMOR OF THE BONE: RESULTS IN FOUR CASES
}

Iwao Takanami, MD, Ken Takeuchi, MD, Masao Naruke, MD, and Susumu Kodaira, MD, Tokyo, Japan

From the Department of Surgery, Teikyo School of Medicine, Tokyo, Japan.

Received for publication March 19, 1998; accepted for publication April 13, 1998.

Address for reprints: Iwao Takanami, MD, Department of Surgery, Teikyo School of Medicine, 2-11, Kaga 2-Chome, Itabashi-Ku, Tokyo, 173 Japan.

J Thorac Cardiovasc Surg 1998;116:649-51

Copyright $\odot 1998$ by Mosby, Inc.

$0022-5223 / 98 \$ 5.00+0 \quad \mathbf{1 2 / 5 4 / 9 0 8 7 2}$
A benign giant cell tumor of the bone (BGCTB) is difficult to categorize because its clinical course cannot be predicted. Approximately 50 cases of a pulmonary metastasis from a BGCTB have been reported in the literature. ${ }^{1}$ A pulmonary metastasis from a BGCTB does not necessarily mean a bad prognosis, but it has been the cause of death in $16 \%$ to $25 \%$ of reported cases. ${ }^{2,3}$ Our method of managing a pulmonary metastasis of a BGCTB is that it should be treated aggressively, as long as the required operation does not impair pul- 
Table I. Patients with pulmonary metastases from a BGCTB: treatment of primary lesion and subsequent local recurrence

\begin{tabular}{|c|c|c|c|c|c|}
\hline Case & $\begin{array}{l}\text { Age/gender } \\
\text { at diagnosis }\end{array}$ & Primary site & Treatment of primary & $\begin{array}{l}\text { Treatment of } \\
\text { local recurrence }\end{array}$ & $\begin{array}{c}\text { Time until pulmonary } \\
\text { metastases diagnosed (mo) }\end{array}$ \\
\hline 1 & $30 / \mathrm{F}$ & Right proximal tibia & Curettage, bone graft & Above-the-knee amputation & 54 \\
\hline 2 & $20 / F$ & Left proximal tibia & Curettage, bone graft & Wide resection & 9 \\
\hline 3 & 24/M & Right distal radius & Curettage, bone graft & Wide resection & 53 \\
\hline 4 & $15 / \mathrm{F}$ & Left proximal tibia & Curettage, bone graft & Wide resection & 33 \\
\hline
\end{tabular}

Table II. Treatment of pulmonary metastases and results

\begin{tabular}{lccc}
\hline Case & $\begin{array}{c}\text { Surgical treatment } \\
\text { (thoracotomy) }\end{array}$ & Lung involvement & $\begin{array}{c}\text { Follow-up } \\
(\text { mo })\end{array}$ \\
\hline 1 & Left & 3 lung nodules & 24 \\
& Left & 3 lung nodules & 26 \\
2 & Left & 1 lung nodule & $76^{*}$ \\
& Right & 6 lung nodules & 24 \\
& Bilateral & 5 right lung nodules & \\
& & 24 left lung nodules & 28 \\
& Right & 2 lung nodules & $76^{*}$ \\
4 & Bilateral & 1 right lung nodule & \\
& & 1 left lung nodule & $39^{*}$ \\
& Bilateral & 7 right nodules & \\
& & 13 left nodules & $24^{*}$ \\
\hline
\end{tabular}

*No evidence of disease.

monary functioning. This article presents our results in treating 4 patients with pulmonary BGCTB metastasis.

Patients and methods. Forty-seven patients with BGCTB were treated at our facility between 1979 and 1997. Four of these patients had a documented pulmonary BGCTB metastasis (Table I). A local recurrence was manifested in all cases. The interval between the operation for local recurrence and the subsequent diagnosis of a pulmonary metastasis was 9 to 54 months (average, 37 months). Plain radiographs and computed tomography scans of the chest were used for the localization of the pulmonary nodules.

Results. The lung was found to be the only site of a metastatic involvement in all 4 patients, who thus underwent a complete resection their pulmonary metastasis (Table II). Two of these patients remained tumor-free after their initial bilateral thoracotomy for their pulmonary metastasis; however, the remaining 2 patients who were surgically treated (cases 1 and 2) experienced the development of a metastatic recurrence in the lung. Both patients did not stay tumor-free after their second thoracotomy and had to undergo a third thoracotomy. None of the 4 patients were given chemotherapy or radiotherapy. Each was followed up at 6month intervals at which time computed tomography scans of the chest were performed. After undergoing the surgical interventions, all patients are still alive (24 to 76 months after the operation).

Discussion. Although the overall BGCTB survival is much higher that for other metastasized lung tumors, BGCTB pul- monary metastasis have been implicated as the cause of death. The natural history of a BGCTB with pulmonary metastasis is as unpredictable as that of the primary BGCTB. On the basis of what is presently known, lesions from BGCTB pulmonary metastasis can be divided into 3 types: (1) those that show spontaneous regression or cessation of growth; (2) those that show continuous slow growth; and (3) those that show rapid growth. It has been reported that metastatic lesions of the lung have disappeared after just a biopsy $^{4}$ and that some pulmonary lesions spontaneously regress. ${ }^{1}$ However, of the few reported cases of an untreated pulmonary BGCTB metastasis, most patients die quite rapidly of the disease. ${ }^{4}$

For therapy, a thoracotomy and a complete excision of the pulmonary nodules has proved successful, ${ }^{4}$ and the literature strongly favors the surgical extirpation of all pulmonary nodules. ${ }^{2}$ Some studies that included patients with BGCTB that was treated by operation and whose follow-ups have been pursued have reported no signs of a BGCTB recurrence at 18 or more years after a resection. ${ }^{2}$ Another study has also found that some patients have become asymptomatic, even though they had a progressive pulmonary disease, and are alive and well. ${ }^{5}$ Further, cases have been reported of recurring and progressive pulmonary metastasis after the surgical removal of previous pulmonary nodules. ${ }^{2}$ In this latter regard, it has been reported that other patients who underwent a partial or a complete excision of their pulmonary nodules also died of the condition. ${ }^{4}$ However, a thoracotomy and the complete excision of recurring, metastatic, pulmonary nodules has been found beneficial for long-term survival. ${ }^{2}$

Our management policy for the 4 cases of this study was a complete extirpation of their pulmonary metastasis, even for the 2 patients who had repeated metastatic recurrences. The 2 patients have also remained disease free at 76 months after the third thoracotomy. As for methods of treatment for a BGCTB metastasis, radiation has been used without apparent success ${ }^{5}$ and chemotherapy has only occasionally proved successful. ${ }^{4}$ Therefore for cases of recurring lung metastasis from a BGCTB, we believe that an aggressive thoracotomy remains the best therapy, provided that the metastasis can be totally removed without impairing pulmonary functioning.

\section{REFERENCES}

1. Kay RM, Eckardt JJ, Seeger LL, Mirra JM, Hak DJ. Pulmonary metastasis of benign giant cell tumor of bone: six histologically 
confirmed cases, including one of spontaneous regression. Clin Orthop 1994;302:231-4.

2. Rock MG, Pritchard DJ, Unni KK. Metastases from histologically benign giant-cell tumor of bone. J Bone Joint Surg 1984;66A: 269-74.

3. Maloney WJ, Vaughan LM, Jones HH, Ross J, Nagel DA. Benign metastasizing giant-cell tumor of bone: report of three cases and review of the literature. Clin Orthop 1989;243:20815.

4. Goldenberg RR, Campbell CJ, Michael B. Giant-cell tumor of bone: an analysis two hundred and eighteen cases. J Bone Joint Surg 1970;52A:619-63.

5. Lasser EC, Hyman T. Metastasizing giant cell tumor: report of an unusual case with indolent bone and pulmonary metastasis. Am J Roentgenol 1957;78:804-11. 